\title{
ANALISIS KEPEMIMPINAN DALAM KEPERAWATAN DI PELAYANAN GAWAT DARURAT
}

\author{
Anita Istiningtyas ${ }^{1}$, Wahyuningsih Safitri ${ }^{2}$ \\ ${ }^{1,2)}$ Universitas Kusuma Husada Surakarta \\ anita.intyas@gmail.com
}

\begin{abstract}
ABSTRAK
Perawat IGD merupakan perawat yang berada di garda depan rumah sakit. Banyak tuntutan yang harus dilakukan terhadap perawat IGD terkait dengan response time, kualifikasi, dan keterampilan. Tidak banyak perawat IGD juga mengeluhkan pekerjaan yang terlalu berat, bahkan dalam satu shift sempat tidak berhenti untuk istirahat. Kepemimpinan dalam keperawatan sangat dibutuhkan agar pelayanan gawat darurat berjalan efektif dan efisien. Kepemimpinan perawat gawat darurat harus menegakkan standar praktik keperawatan darurat profesional yang mendukung lingkungan yang kondusif untuk mengurangi pergantian staf dan peningkatan retensi keperawatan. Tujuan dari penelitian ini untuk menganalisis kepemimpinan keperawatan dalam pelayanan gawat darurat. Penelitian dilakukan dengan Metode Deskriptif Analitik. Analisis dilakukan secara univariat dengan distribusi frekuensi. Populasi dalam penelitian adalah seluruh perawat IGD. Hasil penelitian ini menunjukkan bahwa kepemimpinan transformasional kepala ruang IGD untuk semua faktor mayoritas dalam kategori tinggi, sedangkan kepemimpinan transaksional untuk faktor 5 dan faktor 6 dalam kategori tinggi serta faktor 7 dalam kategori sedang.
\end{abstract}

Kata kunci : gawat darurat, kepemimpinan, keperawatan

\begin{abstract}
Emergency nurses are nurses who are in the front line of the hospital. There are many demands must be placed on emergency nurses regarding response time, qualication and skills. Many emergency nurses complain that the work is too heavy, even in one shift they do not have time to take a break. Leadership in nursing is urgently needed so that emergency services can uphold standards of professional emergency nursing practice that foster to reduced staff turnover and increased nursing retention. This study aims to analyze nursing leadership in emergency services. The research was conducted using a descriptive-analytic method. The analysis was carried out univariate with a frequency distribution. The population in the study was a nurse in the emergency department. Research results show that the transformational leadership of the head of the emergency department for all factors is the majority in the high category, while the transactional leadership for factor 5 and factor 6 was in the high category and factor 7 was in the medium category.
\end{abstract}

Keywords : emergency, leadership, nursing, 


\section{PENDAHULUAN}

Kepemimpinan adalah kunci penting dalam mencapai kualitas perencanaan tim dan keberhasilan dalam kondisi kegawatdaruratan. Kondisi kegawatdaruratan yang dimaksudkan disini adalah semua situasi yang menuntut kerja tim multidisiplin serta sumberdaya teknis yang maju dan berbeda untuk basic life support di pelayanan gawat darurat. Kepemimpinan yang efektif dikaitkan dengan peningkatan hasil kerja tim dan dan peningkatan keterlibatan staf dalam pelayanan gawat darurat. Situasi kegawatdaruratan sering ditandai dengan kompleksitas yang tinggi, ketidakpastian, kekacauan dan ambiguitas sehingga membutuhkan tindakan yang terkoordinasi dan tersinkronisasi (Amado Martins et al., 2017)2014.

Pada laporan tahunan 2015 di United Kingdom didapatkan data bahwa komisi kualitas keperawatan menyatakan sebanyak $84 \%$ layanan dinilai tidak memadai juga memiliki kepemimpinan yang tidak memadai (Lloyd \& Clegg, 2016). Penelitian di Indonesia pada tahun 2017 menunjukkan data bahwa kepemimpinan yang diterapkan di IGD -RS mayoritas adalah demokratis sebanyak $58 \%$ sedangkan $42 \%$ merupakan tipe kepemimpinan partisipatif. Tipe kepemimpinan di IGD tidak bisa dipilih salah satu untuk diterapkan di sebuah bangsal khususnya gawatdarurat, karena sesuai konsepnya bahwa semua tipe kepemimpinan itu baik asalkan ditempatkan pada posisi dan situasi kondisi yang sesuai (Nurhanifah \& Firdaus, 2017).

Ketidakmampuan dalam penempatan kepemimpinan yang tepat di pelayanan gawat darurat akan menimbulkan dampak yang signifikan. Salah satu dampak yang bisa terjadi adalah tidak terkoordinasinya sistem triase yang baik (Lloyd \& Clegg, 2016). Kepemimpinan yang buruk akan mempengaruhi semangat kerja, motivasi dan iklim kerja yang tidak kondusif pula (Temu, 2018).

Hasil studi pendahuluan didapatkan data bahwa kepala ruang IGD membutuhkan banyak keputusan medis dalam penanganan pasien sehingga lebih banyak koordinasi dengan tenaga medis dalam hal ini dokter. Pengambilan keputusan mandiri sebagai pimpinan seorang perawat disampaikan belum banyak dilakukan karena memang kebutuhan di lahan masih atas wewenang dokter. Berdasarkan fenomena dan data yang muncul tersebut, maka peneliti tertarik untuk melakukan penelitian tentang analisis kepemimpinan dalam keperawatan di pelayanan gawat darurat.

Tujuan dari penelitian ini adalah untuk menganalisis kepemimpinan transformasional dan kepemimpinan transaksional dari kepemimpinan keperawatan di pelayanan gawat darurat. Ruang lingkup dari penelitian ini adalah melihat persepsi perawat pelaksana terhadap kepemimpinan kepala ruang pelayanan gawat darurat.

\section{METODOLOGI}

Jenis Penelitian ini adalah penelitian kuantitatif. Penelitian kuantitatif merupakan proses dalam mencari pengetahuan dengan menggunakan data berupa angka sebagai cara atau alat untuk melakukan analisis terhadap apa yang ingin dicari. Rancangan yang digunakan dalam penelitian ini adalah deskriptif analitik.

$$
\text { Metode pengambilan sampel }
$$
menggunakan Metode Total Sampling sehingga jumlah sampel dalam penelitian ini adalah 33 responden perawat pelaksana di RS Assalam Gemolong dan RSUD Gemolong. Tidak ada kriteria inklusi ataupun ekslusi dalam sampel karena peneliti hanya ingin melihat persepsi perawat pelaksana terhadap kepemimpinan kepala ruang.

Alat penelitian yang digunakan dalam 
penelitian ini adalah peneliti mengadopsi dari kuesioner MLQ. Alat ukur ini digunakan untuk mengetahui dan mengidentifikasi seberapa baik kepemimpinan transformasional dan transaksional yang diterapkan (Schlossman, 2011). Analisis univariat dalam penelitian ini kepemimpinan dalam pelayanan gawat darurat. Analisisnya menggunakan distribusi frekuensi karena data dengan skala kategorik.

HASIL

Teknik pengolahan data dilakukan melalui 4 tahap yaitu pertama dilakukan editing. Dari tahap editing peneliti melakukan koreksi terhadap data yang masuk dan terkumpul dari responden apakah sudah sesuai dengan isian atau tidak. Tahap kedua dilakukan coding yaitu memberikan kode-kode dengan angka terhadap data yang bersifat kategorik seperti kepemimpinan tinggi (kode 1), kepemimpinan sedang (kode 2), kepemimpinan rendah (kode 3). Tahap ketiga dilakukan entry data yaitu mengolah data ke dalam descriptive analitic untuk mendapatkan kesimpulan dari distribusi frekuensi. Tahap keempat adalah tabulating yaitu dengan membuat kelompok kelompok data dalam bentuk tabel untuk memudahkan dalam pembacaan kesimpulan. Semua data diolah menggunakan SPSS 18.0.

1. Identifikasi kepemimpinan transformasional

a. Faktor 1 (Pengaruh Ideal)

Table 1. Faktor I (Pengaruh Ideal)

Kepemimpinan Karu IGD $(n=33)$

\begin{tabular}{lcc}
\hline Kategori & n & \% \\
\hline Tinggi & 25 & 75.8 \\
Sedang & 7 & 21.2 \\
Rendah & 1 & 3 \\
\hline Total & 33 & 100 \\
\hline
\end{tabular}

b. Faktor 2 (Pertimbangan Individu)

Tabel 2. Faktor 2 (Pertimbangan Individu) Kepemimpinan Karu IGD $(n=33)$

\begin{tabular}{lcc}
\hline Kategori & n & \% \\
\hline Tinggi & 26 & 78,8 \\
Sedang & 6 & 18,2 \\
Rendah & 1 & 3 \\
\hline Total & 33 & 100 \\
\hline
\end{tabular}

c. Faktor 3 (Stimulasi Intelektual)

Tabel 3. Faktor 3 (Stimulasi

Intelektual) Kepemimpinan Karu IGD (n=33)

\begin{tabular}{lcc}
\hline Kategori & $\mathbf{n}$ & $\mathbf{\%}$ \\
\hline Tinggi & 22 & 66,7 \\
Sedang & 10 & 30,3 \\
Rendah & 1 & 3 \\
\hline Total & 33 & 100 \\
\hline
\end{tabular}

d. Faktor 4 (Motivasi Inspirasional)

Tabel 4. Faktor 4 (Motivasi Inspirasional) Kepemimpinan Karu IGD ( $n=33)$

\begin{tabular}{lcc}
\hline Kategori & n & \% \\
\hline Tinggi & 22 & 66,7 \\
Sedang & 10 & 30,3 \\
Rendah & 1 & 3 \\
\hline Total & 33 & 100 \\
\hline
\end{tabular}

2. Identifikasi kepemimpinan transaksional

a. Faktor 5 (Penghargaan Kontingen)

Tabel 5. Faktor 5 (Penghargaan Kontingen) Kepemimpinan Karu IGD $(n=33)$

\begin{tabular}{lcc}
\hline Kategori & n & $\mathbf{\%}$ \\
\hline Tinggi & 20 & 60,6 \\
Sedang & 13 & 39,4 \\
Rendah & 0 & 0 \\
\hline Total & 33 & 100 \\
\hline
\end{tabular}


b. Faktor 6 (Manajemen eksepsi aktif)

Tabel 6. Faktor 6 (Manajemen eksepsi aktif) Kepemimpinan Karu IGD $(n=33)$

\begin{tabular}{lcc}
\hline Kategori & $\mathbf{n}$ & $\mathbf{\%}$ \\
\hline Tinggi & 23 & 69,7 \\
Sedang & 10 & 31,3 \\
Rendah & 0 & 0 \\
\hline Total & 33 & 100 \\
\hline
\end{tabular}

c. Faktor 7 (Kepemimpinan yang bebas)

Tabel 7. Faktor 7 (Kepemimpinan yang bebas) Kepemimpinan Karu IGD $(n=33)$

\begin{tabular}{lcc}
\hline Kategori & $\mathbf{n}$ & $\mathbf{\%}$ \\
\hline Tinggi & 14 & 42,4 \\
Sedang & 17 & 51,5 \\
Rendah & 2 & 6,1 \\
\hline Total & 33 & 100 \\
\hline
\end{tabular}

\section{PEMBAHASAN}

1. Analisis Kepemimpinan Transformasional Kepala Ruang Pelayanan Gawat Darurat

Kepemimpinan transformasional ini mendorong kesiapan perawat untuk melakukan usaha yang lebih dari seharusnya, memuaskan seorang pemimpin dan melihat persepsi keefektifan pemimpin (Gore \& Gore, 2017). Kepemimpinan tipe ini juga menekankan pada motivasi antar anggota, mampu menginspirasi anggota, saling menghormati anggota, saling mengkomunikasikan tujuan bersama dengan anggota, dan mendorong kepuasan pencapaian kinerja (Sfantou et al., 2017).

Berdasarkan hasil penelitian diketahui bahwa mayoritas persepsi perawat tentang faktor 1 (Pengaruh Ideal) berada dalam kategori tinggi yaitu sebanyak 75,8\%. Pengaruh ideal merupakan tindakan yang dilakukan oleh pemimpin dalam membangkitkan emosional para pengikutnya (Riniwasitaningsih, 2015)(Riniwasitaningsih, (Riniwasitaningsih, 2015). Pengaruh Ideal dalam penelitian ini bisa dijelaskan dalam artian adalah kemampuan seorang kepala ruang IGD dalam membangkitkan atau menggugah emosional perawat pelaksana di IGD.

Kemampuan Faktor 1 (Pengaruh Ideal) ditunjukkan dengan pemimpin mampu memegang kepercayaan bawahan, mempertahankan iman dan rasa hormat bawahan, mampu menunjukkan dedikasi pada bawahan, mampu memikat harapan harapan bawahan, dan mampu bertindak sebagai role model (Bass \& Aviolo, 2004). Hasil penelitian menunjukkan bahwa karakteristik yang menonjol adalah bahwa perawat pelaksana mempunyai persepsi akan keyakinan penuh pada kepala ruang IGD dalam proses memimpin, jika dibandingkan dengan adanya rasa senang dan bangga orang lain ketika berada didekat kepala ruang IGD. Kepala ruang IGD merupakan satu satunya staf di pelayanan IGD yang mempunyai tingkat Pendidikan Profesi Ners, sehingga menilik dari hal tersebut bahwa kompetensi yang dimiliki mampu menunjukkan kemampuannya dihadapan para perawat pelaksana.

Tipe pemimpin transformasional memenangkan kepercayaan dan rasa hormat dari para pengikutnya dan pengikut berusaha untuk meniru pemimpinnya. Seorang pemimpin yang telah menjadi panutan, tidak mungkin ada perlawanan dari bagian pengikut saat sebuah keputusan baru diambil (Renjith \& George, 2016).

Berdasarkan hasil penelitian diketahui bahwa mayoritas persepsi perawat tentang Faktor 2 (Pertimbangan Individu) 
berada dalam kategori tinggi yaitu sebanyak $78,8 \%$. Pertimbangan individu ditunjukkan dengan pemberian support system bagi pengikutnya bisa berupa dukungan moril atau pelatihan (Riniwasitaningsih, 2015). Pada penelitian ini Pertimbangan Individu kepala ruang IGD adalah kemampuan kepala ruang IGD dalam memberikan dukungan dan dorongan baik morel maupun fisik bagi perawat pelaksana. Pertimbangan Individu dalam penelitian ini lebih menekankan pada kemampuan kepala ruang IGD dalam melakukan pendekatan secara individu bagi perawat pelaksana agar tercapai kesejahteraan diri perawat pelaksana.

Kemampuan Faktor 2 (Pertimbangan Individu) seorang pemimpin ditunjukkan dengan menjadi pemimpin yang penuh kasih, bertindak sebagai mentor bagi pengikut dan atas kreativitas serta inovasi. Seorang pemimpin transformasional adalah master keterampilan komunikasi dan menunjukkan keunggulan kemampuan interpesonal. Pemimpin transformasional melalui Faktor

2 (Pertimbangan Individu) menunjukkan kepedulian dan kasih sayang yang tulus terhadap para pengikutnya. Para pengikut didukung berdasarkan kebutuhan dan dibina berdasarkan bakat. Para pengikut seringkali diberdayakan untuk mengambil keputusan dan diberikan dukungan yang diperlukan untuk melaksanakan keputusan tersebut. Seorang pemimpin transformasional tertarik pada pengembangan dan pertumbuhan karyawan yang berkelanjutan (Renjith \& George, 2016).

Berdasarkan hasil penelitian diketahui bahwa mayoritas persepsi perawat tentang Faktor 3 (Stimulasi Intelektual) berada dalam kategori tinggi yaitu sebanyak $78,8 \%$. Stimulasi Intelektual merupakan kemampuan pemimpin dalam menyadarkan pengikutnya akan permasalahan yang terjadi dalam kelompok dan menyelesaikannya dengan perspektif yang baru (Riniwasitaningsih, 2015). Kemampuan stimulasi intelektual dalam penelitian ini adalah kemampuan atau perilaku kepala ruang IGD dalam meningkatkan kesadaran dan peran serta dari perawat pelaksana untuk mengenal dan menyelesaikan masalah yang terjadi di IGD.

Pemimpin dengan faktor ini akan mendorong dan menghargai ide-ide inovatif dan kreatif dari pengikut. Pengikut tidak pernah disalahkan atau dikritik di depan umum atas kesalahan yang dilakukan. Melalui stimulasi intelektual seorang pemimpin transformasional merangsang pemikiran kritis, meningkatkan pemecahan masalah dan memberdayakan pengikut (Gore \& Gore, 2017). Seorang pemimpin transformasional dengan faktor stimulasi intelektual ini mendorong pengikut untuk berpikir out of the box dan mendorong imajinasi pengikut. Dalam penelitian ini, kepala ruang secara intelektual merangsang perawat pelaksana untuk berpikir secara rasional dan bertindak secara ilmiah untuk meningkatkan tindakan keperawatan gawat darurat berdasarkan evidence based (Renjith \& George, 2016).

Berdasarkan hasil penelitian diketahui bahwa mayoritas persepsi perawat tentang Faktor 4 (Motivasi Inspirasional) berada dalam kategori tinggi yaitu sebanyak $66,7 \%$. Motivasi Inspirasional merupakan kemampuan seorang pemimpin untuk menggambarkan usaha-usaha pengikutnya melalui simbol-simbol, menyampaikan visi dengan cara yang menarik dan mencontohkan secara langsung perilaku yang sesuai (Riniwasitaningsih, 2015). Motivasi insiprasional dalam penelitian ini 
merupakan kemampuan kepala ruang IGD dalam menyampaikan visi pelayanan gawat darurat kepada perawat pelaksana dengan cara yang menarik atau berperilaku yang sesuai.

Inspirasi dan motivasi adalah dua komponen utama dari kepemimpinan transformasional. Seorang pemimpin transformasional memotivasi pengikut untuk mencapai tujuan dan sasaran organisasi sambil menginspirasi pengikut untuk mencapai tujuan individu sendiri. Upaya menyelaraskan kebutuhan individu dengan kebutuhan organisasi merupakan strategi penting dari motivasi inspirasional. Para pemimpin transformasional berusaha untuk memupuk semangat kerja tim dan komitmen. Seorang pemimpin transformasional memperjelas visi, misi dan tujuan strategis organisasi dan menciptakan sense of purpose yang kuat di antara para pengikut (Renjith \& George, 2016).

2. Analisis kepemimpinan transaksional kepala ruang pelayanan gawat darurat

Kepemimpinan transaksional lebih menekankan pada hubungan saling memberi dan menerima antara pemimpin dan anggotanya (Gore \& Gore, 2017). Kepemimpinan tipe ini lebih cenderung sebagai changed agent atau manajer perubahan dalam mencapai kinerja dengan anggota (Sfantou et al., 2017).

Berdasarkan hasil penelitian diketahui bahwa mayoritas persepsi perawat tentang Faktor 5 (Penghargaan Kontingen) berada dalam kategori tinggi yaitu sebanyak $60,6 \%$. Penghargaan kontingen merupakan kemampuan pemimpin yang menjelaskan bahwa pengikut akan mendapatkan imbalan dan harapan apabila melakukan kinerja sesuai dengan yang disepakati (Riniwasitaningsih,
2015).

Penghargaan Kontingen pada penelitian ini masuk dalam kategori tinggi terutama untuk karakteristik kepala ruang IGD yang selalu menginformasikan kepada perawat pelaksana apa yang menjadi tanggungjawab dalam kinerja masing-masing perawat dibandingkan dengan memberikan reward ketika perawat melakukan pencapaian tujuan dan memberikan perhatian pada perawat pelaksana. Peran tersebut berkaitan dengan fungsi pengarahan sesorang kepala ruang.

Berdasarkan hasil penelitian diketahui bahwa mayoritas persepsi perawat tentang Faktor 6 (Manajemen Eksepsi Aktif) berada dalam kategori tinggi yaitu sebanyak 69,7\%. Manajemen eksepsi aktif merupakan kemampuan seorang pemimpin untuk menilai apakah pengikut memberi tahu orang lain tentang persyaratan pekerjaan dan kepuasan dengan standar kinerja (Bass \& Aviolo, 2004).

Pada penelitian ini dapat dijelaskan bahwa kemampuan kepala ruang dalam manajemen eksepsi aktif adalah upaya yang dilakukan kepala ruang dalam memantau kinerja perawat pelaksana dan masalah masalah yang muncul dalam tim serta adanya upaya untuk memperbaiki dari kesalahan yang ada. hal tersebut sangat sesuai dengan fungsi manajemen yaitu pengawasan. Standar kinerja sangat diperlukan bagi perawat pelaksana terutama di pelayanan gawat darurat karena berkenaan dengan tindakan tindakan yang berisiko mengancam nyawa pasien. Hal ini sangat diperlukan, selain untuk melaksanakan tindakan keperawatan secara professional juga sebagai perlindungan hokum bagi perawat dalam penanganan kasus pasien yang berisiko. 
Berdasarkan hasil penelitian diketahui bahwa mayoritas persepsi perawat tentang Faktor 7 (Kepemimpinan yang Bebas) berada dalam kategori sedang yaitu sebanyak $51,5 \%$. Kepemimpinan yang bebas merupakan karakteristik pemimpin dimana akan membiarkan pengikut melakukan hal sesuai dengan keinginan mereka sendiri (Bass \& Aviolo, 2004). Kepemimpinan ini dalam beberapa teori cenderung disebut dengan Laissez Fairre atau passive avoidant. Suatu perilaku yang tidak mengupayakan adanya kepemimpinan, akan mulai bertindak jika ada kesalahan dan menghindari sebuah pengambilan keputusan (Riniwasitaningsih, 2015).

Berdasarkan teori diatas dapat dijelaskan bahwa dalam penelitian ini untuk Faktor 7 (Kepemimpinan yang bebas) memang tidak menonjol ada pada kepala ruang IGD. Hal ini dapat dijelaskan bahwa mayoritas karakteristik perawat pelaksana di IGD adalah masa kerja 5 tahun, sementara paling banyak adalah masa kerja 1 tahun. Dalam rentang masa kerja 1 sampai 5 tahun, masih bisa dikatakan bahwa pengalaman kerja masih dalam tingkat menengah. Pengalaman kerja dalam tingkat menengah ini, seorang perawat pelaksana masih membutuhkan arahan dan bimbingan dari pemimpin, sehingga tidak bisa dibiarkan begitu saja melakukan tindakan sesuai yang diinginkan. Hal ini sesuai dengan teori yang menyatakan bahwa kepemimpinan yang bebas lebih sesuai diaplikasikan untuk meningkatkan kinerja bila pengikut adalah seorang pegawai senior yang sangat berpengalaman di bidang pekerjaannya karena akan sudah mengerti tanggungjawab dan kewajiban masing masing sehingga pemimpin hanya tinggal memberikan kebijaksanan umum (Sfantou et al., 2017).

\section{SIMPULAN DAN SARAN}

Simpulan dalam penelitian ini adalah Kepemimpinan transformasional kepala ruang IGD mayoritas untuk Faktor 1 (Pengaruh Ideal), Faktor 2 (Pertimbangan Individu), Faktor 3 (Stimulasi Intelektual) dan Faktor 4 (Motivasi Inspirasional) berada dalam kategori tinggi, sedangkan Kepemimpinan transaksional kepala ruang IGD mayoritas untuk Faktor 5 (Penghargaan Kontingen) dan Faktor 6 (Manajemen Eksepsi Aktif) berada dalam kategori tinggi serta Faktor 7 berada dalam kategori sedang.

Saran dari penelitian ini untuk rumah sakit adalah perlunya dilakukan pelatihan kepemimpinan untuk memahamkan konsep konsep kepemimpinan dan implikasi tipe tipe kepemimpinan yang tepat dalam situasi yang tepat secara berkala. Saran bagi peneliti selanjutnya adalah untuk melakukan penelitian secara kualitatif untuk menggali harapan harapan perawat pelaksana terkait karakteristik kepemimpinan yang sesuai di pelayanan gawat darurat khusus dalam lingkup kepemimpinan tranformasional dan transaksional serta mengambil sampel dalam jumlah yang lebih besar atau bisa menggunakan Rumah Sakit dengan tipe yang lebih besar untuk mendapatkan sejumlah perawat pelaksana di ruang IGD.

\section{DAFTAR PUSTAKA}

Amado Martins, J. C., De Sousa, A. C. V., Diogo Abrantes, A. R., Da Silva Pinto, C. S., De Almeida Gomes, C. I., Oliveira Martins, D. J., Dias Coutinho, V. R., Baptista, R. C. N., De Oliveira, L. M. N., \& Fernandes, M. I. D. (2017). Communication and leadership in emergency situations: Systematic literature review and recommendations for practice. Clinical Nursing Studies, 6(2), 55. https://doi. org/10.5430/cns.v6n2p55 
Bass, B. M., \& Aviolo, B. J. (2004). Sample Items From the Multifactor Leadership Questionnaire ( MLQ ) Form 5X-Short. Multifactor Leadership Questionnaire, 2004.

Gore, C. A., \& Gore, C. A. (2017). An Analysis of ED Nurse Opinion of Their ED Nurse Manager Leadership Characteristics and Outcomes.

Lloyd, A., \& Clegg, G. (2016). From leader to leadership in emergency care. Nursing Times, 112(41-42), 10-12.

Nurhanifah, D., \& Firdaus, M. R. (2017). Hubungan antara Gaya Kepemimpinan Kepala Ruang terhadap Pemeriksan TTV di Ruang IGD Rumah Sakit. Healthy-Mu Journal, 1(2, Februari), 59-63.

Renjith,V., \& George,A.(2016). Transformational Leadership in Nursing. Transformational Leadership in Nursing, 2(2), 112-118. https://doi.org/10.1891/9780826193995

Riniwasitaningsih. (2015). Pengaruh gaya kepemimpinan transformasional dan budaya organisasi terhadap kinerja karyawan (pada Perusahaan AJB Bumiputra 1912 Kantor Cabang .... ... Dan Budaya Organisasi Terhadap Kinerja Karyawan ..., 61-72. http://library.um.ac. $\mathrm{id} /$ ptk/index.php? $\mathrm{mod}=$ detail\&id $=68233$

Schlossman, D. (2011). $\square \square$ No Title No Title. Journal of Chemical Information and Modeling, 53(9), 1689-1699.

Sfantou, D., Laliotis, A., Patelarou, A., SifakiPistolla, D., Matalliotakis, M., \& Patelarou, E. (2017). Importance of Leadership Style towards Quality of Care Measures in Healthcare Settings: A Systematic Review. Healthcare, 5(4), 73. https://doi.org/10.3390/ healthcare 5040073

Temu, S. (2018). Pengaruh Kepemimpinan Yang Berintegritas Terhadap Kinerja Perawat. Jurnal Keperawatan, 10(1), 9-18. http:// garuda.ristekbrin.go.id/documents/ detail/1101612 